\title{
Green Determination of Urea in Moisturizers by Diffuse Reflectance Spectroscopy
}

\section{Paulo Roberto A. Bueno Toledo, Aline Theodoro Toci, Helena Redigolo Pezza} \& Leonardo Pezza

To cite this article: Paulo Roberto A. Bueno Toledo, Aline Theodoro Toci, Helena Redigolo Pezza \& Leonardo Pezza (2017) Green Determination of Urea in Moisturizers by Diffuse Reflectance Spectroscopy, Analytical Letters, 50:12, 2030-2043, DOI: 10.1080/00032719.2016.1255223

To link to this article: https://doi.org/10.1080/00032719.2016.1255223

Accepted author version posted online: 29

Jun 2017.

Published online: 14 Aug 2017.

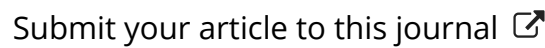

Џ Article views: 45

View Crossmark data \lceil 


\title{
Green Determination of Urea in Moisturizers by Diffuse Reflectance Spectroscopy
}

\author{
Paulo Roberto A. Bueno Toledo ${ }^{a}$, Aline Theodoro Toci ${ }^{b}$, Helena Redigolo Pezza ${ }^{a}$, and \\ Leonardo Pezza ${ }^{a}$
}

anstitute of Chemistry, São Paulo State University - UNESP, São Paulo, Brazil; 'Latin American Institute of Science of Life and Nature, Federal University of Latin American Integration - UNILA, Paraná, Brazil

\begin{abstract}
This manuscript describes the development and application of a simple, inexpensive, and green method for the quantification of urea in skin moisturizer creams, using a combined spot test/diffuse reflectance spectroscopy procedure. The method is based on the derivatization of urea with a chromogenic reagent ( $p$-dimethylaminocinnamaldehyde) in acidic methanol, yielding a colored compound on the surface of filter paper. The reaction parameters were optimized using chemometric experimental design. Reflectometric measurements of the colored compound were performed at $530 \mathrm{~nm}$, the wavelength of maximum absorption. The linear dynamic range was from 25 to $750 \mathrm{mg} \mathrm{L}^{-1}$. The detection and quantification limits were 6.50 and $21.65 \mathrm{mg} \mathrm{L}^{-1}$, respectively. The method was successfully used for the determination of urea in skin moisturizer creams, demonstrating that it is a reliable eco-friendly alternative.
\end{abstract}

\section{ARTICLE HISTORY}

Received 17 August 2016 Accepted 27 October 2016

\section{KEYWORDS}

Diffuse reflectance spectroscopy; green analytical methodology; moisturizer cream; spot test; urea

\section{Introduction}

The use of urea in dermatological products has increased considerably in recent years, due to its effects on human skin and its low cost. Studies have demonstrated that urea is able to increase the water content of the top layers of the skin, enhancing hydration (Wohlrab 1986; Serup 1991; Loden et al. 2001). Therefore, urea is added to dermatological products to increase the hydration capacity of the skin, with concentrations in moisturizer creams ranging from 1 to $10 \%(\mathrm{w} / \mathrm{w})$ (Küster et al. 1997; Ademola et al. 2002).

Normal skin contains approximately $1 \%$ urea and its deficiency may lead to atopic dermatitis or dry skin. Decreased water content of the epidermis alters the barrier properties of the skin, favoring the penetration of xenobiotics, reducing the itching threshold, and increasing the predisposition to cutaneous inflammation (Elias 2007). Dry skin may lead to the development of various dermatoses, such as atopic eczema, ichthyosis, and contact eczema (Fluhr et al. 2006). The application of dermatological formulations containing oils and hygroscopic components such as urea contributes to the restoration of the cutaneous barrier, maintaining a sufficient level of water. The effects are perceived immediately after application, with improvement of common signs of dry skin such as roughness and peeling

CONTACT Leonardo Pezza pezza@iq.unesp.br $\Theta$ Institute of Chemistry, São Paulo State University - UNESP, R. Prof. Francisco Degni 55, P.O. Box 355, 14800-900, Araraquara, São Paulo, Brazil.

Color versions of one or more of this figures in this article can be found online at www.tandfonline.com/lanl. 
(Lodén 2003). The restorative effect of urea on the skin may reduce irritation, as demonstrated experimentally using sodium lauryl sulfate on skin previously treated with cream containing urea (Lodén 1996; Buraczewska et al. 2007). As an active ingredient of moisturizer creams, urea may also enhance the penetration of other compounds present in the formulation. However, in the presence of allergy or sensitivity to any component of the formulation, the presence of urea may lead to skin irritation (Wohlrab 1979; Couto, Oliveira, and Alonso 2005).

The vehicle most frequently used in moisturizers is the Croda base emulsion. The Cosmetics Technical Chamber of the National Health Surveillance Agency (Brazil) has warned of the use of urea during pregnancy because this compound easily crosses the placental barrier, increasing the skin penetration of other active substances that may be harmful to the fetus. Therefore, it is recommended that products containing more than 3\% urea in their composition should be labeled Do Not Use During Pregnancy. The US Cosmetic Ingredient Review (CIR) Expert Panel considered the database on urea sufficient to assess its safety, concluding that urea is safe as used in cosmetic products. The Food and Drug Administration (FDA) reports no safety concerns related to the use of urea at concentrations of up to $10 \%$ in skin care products (FDA 2006).

Considering the importance of quality control of cosmetic products and the use of urea in dermatologic and cosmetic therapy, reliable methods are required for its determination. Several techniques have been reported for the quantification of urea in cosmetics and other matrices, but there is no generally accepted standard method for its analysis, due to the diversity of products containing urea in their compositions. The complexity of the matrix has resulted in only a few methods being used for the determination of urea in cosmetics (Table 1). Reported techniques include colorimetry (Knorst, Neubert, and Wohlrab 1997), fluorometry (Iida et al. 2004), spectrophotometry (Bojic, Radovanovic, and Dimitrijevic 2008), electrochemistry (Wałcerz, Głąb, and Koncki 1998; Koncki, Chudzik, and Walcerz 1999, Magellan), and hydrophilic interaction chromatography with ultraviolet detection (Dallet et al. 2002; Doi et al. 2009).

Disadvantages of colorimetric methods include reactions among components of the chromogenic reagent, instability of the colored compound formed in the reaction, and poor reproducibility (Knorst, Neubert, and Wohlrab 1997). Spectrophotometric techniques have the advantages of being simple and requiring instrumentation that is common in many laboratories, although a difficulty is that there may be overlap of the spectra of compounds, necessitating the use of a separation technique or mathematical treatments. For example, Bojic, Radovanovic, and Dimitrijevic (2008) reported that kinetic methods provided good sensitivity for the determination of urea, although rigorous control of the reaction parameters was required. Electrochemical techniques were developed for the quantification of urea (Wałcerz, Głąb, and Koncki 1998; Koncki, Chudzik, and Walcerz 1999), although these methods have may have poor reproducibility, hindering their application. Procedures using chromatographic separation are widely used for urea analysis, due to their low limits of detection and quantification, robustness, reproducibility, possibility of automation, the elimination of interferences, and possibility of simultaneous analysis of various analytes. However, these methods use large quantities of acetonitrile and require laborious pretreatment steps involving extraction with hexane and acetonitrile and filtration, resulting in the disposal of large quantities of solvents after the analyses (Dallet et al. 2002; Clark et al. 2007; Doi et al. 2009). 


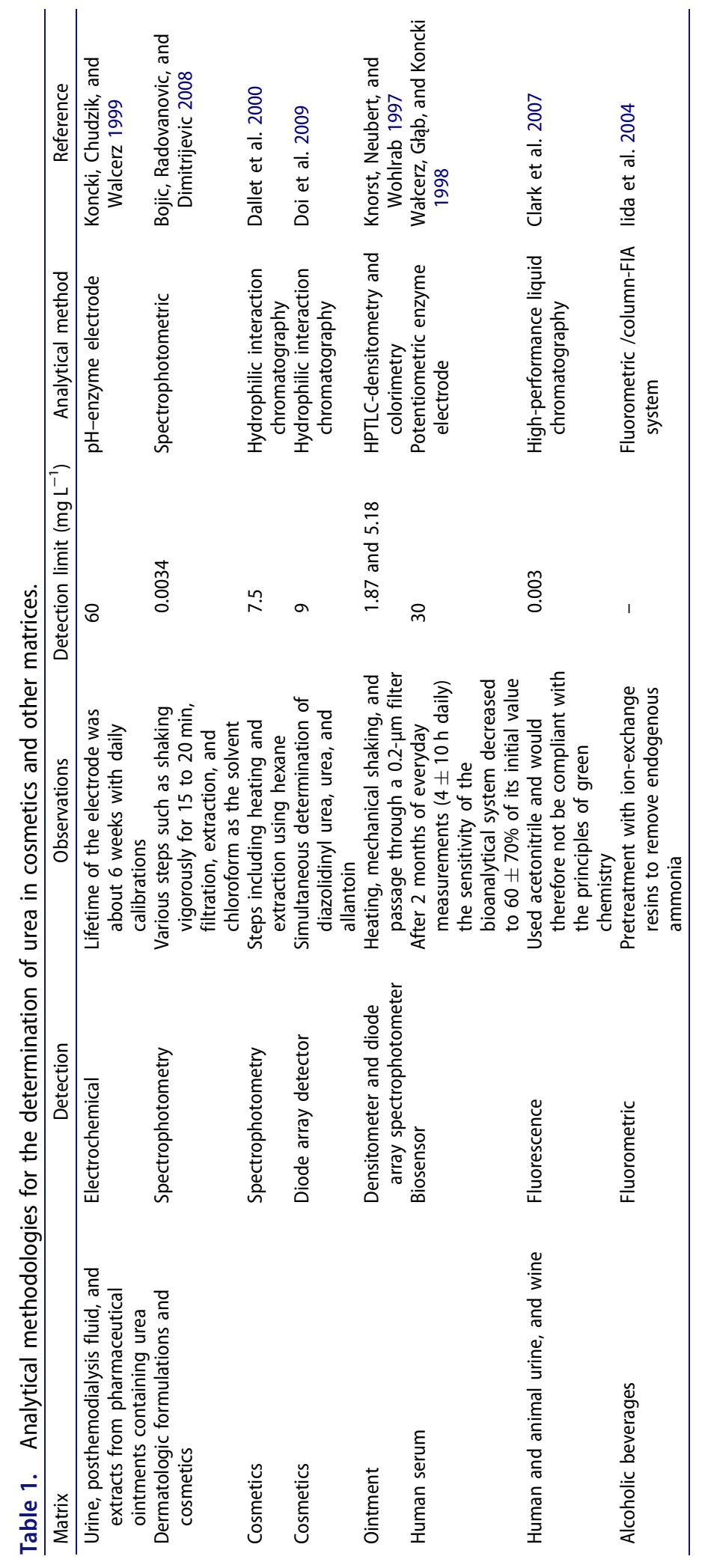


Luminescence methods offer selectivity and provide low limits of detection and quantification but are limited to fluorescent and phosphorescent molecules. Flow injection analysis (FIA) systems allow the performance of kinetic studies, low sample consumption, rapid analysis, and simple instrumentation; a disadvantage of these systems is the possible occurrence of bubble formation, which can interfere in the analysis, and decreased sensitivity. A disadvantage of FIA, compared to other methods, is poor flexibility, since whenever a change is required, it is necessary to re-evaluate numerous parameters or even reconfigure the analyzer (Iida et al. 2004). The Kjeldahl technique is the official method for determining urea in cosmetics and dermatological formulations. This methodology has several disadvantages, notably the time required, poor selectivity, small linear dynamic range, and lengthy pretreatment steps to remove interfering species. It also requires the use of high temperatures and concentrated acids, presenting risks to the operator. The Kjeldahl method requires approximately $3 \mathrm{~h}$ for the determination of urea (AOAC 2000; Sáez-Plaza et al. 2013a; Sáez-Plaza et al. 2013b).

This purpose of the present work was to provide a method that is safer for the operator and the environment by complying with the principles of green chemistry (Anastas and Kirchhoff 2002) as well as being fast, simple, and inexpensive. As an alternative methodology that is eco-friendly, the combination of diffuse reflectance spectroscopy with spot tests has been described for the determination of drugs in routine clinical procedures (Gotardo et al. 2004; Lima et al. 2009: Capiau et al. 2016; Ehiwe et al. 2016), food analysis (Luiz, Pezza, and Pezza 2012; Rossini et al. 2016), quality control (Inagaki et al. 2016; Rahoui et al. 2016), and determination of contaminants (Tubino, Rossi, and Magalhães 1997; Okparanma, Coulon, and Mouazen 2014).

Spot tests using filter paper coupled with diffuse reflectance spectroscopy have gained attention in the literature because this approach offers speed, analytical simplicity, and considerably reduced reagent consumption using, on average, $10-20 \mu \mathrm{L}$ of each reagent (Tubino, Rossi, and Magalhães 1997). Here, an alternative green methodology using spot tests combined with diffuse reflectance spectroscopy was developed for the determination of urea in cosmetic moisturizer formulations. The methodology is simple, sensitive, fast, and inexpensive. The generated waste is minimal and has low toxicity. No complex pretreatment steps are required, minimizing risks to the operator and the environment. Furthermore, the reflectance measurements may be performed in situ using a simple homemade reflectometer or a low-cost portable battery-powered diffuse reflectance spectrophotometer. These features make the technique highly attractive. The method is based on the derivatization of urea to form a colored product using $p$-dimethylaminocinnamaldehyde in an acidified methanol, yielding a colored compound on the surface of filter paper at $530 \mathrm{~nm}$. Experimental design was used to optimize the measurement conditions.

\section{Experimental}

\section{Apparatus}

The reflectance measurements were performed using an integrating sphere (ISP-REF, Ocean Optics, Dunedin, USA) connected to a fiber optic minispectrometer fitted with a 2048 pixel Sony ILX511 CCD array detector (USB2000, Ocean Optics). The concentrations of the colored compound produced in the spot tests were determined by reference to a 
calibration curve. The absorption spectra were recorded versus a reagent blank. SpectraSuite software (Ocean Optics) was used for acquisition and storage of spectra. Eppendorf $(10$ to $100 \mu \mathrm{L})$ and Brand micropipettes (100 to $1,000 \mu \mathrm{L}$ ) were used to measure the volumes in the experiments.

\section{Chemicals}

Whatman No. 1 qualitative filter paper was used as the solid support. All reagents used were analytical grade and were used without any prior purification. The chromogenic reagent solution consisted of $p$-dimethylaminocinnamaldehyde (Acros, $98 \%$ ) and hydrochloric acid (Mallinckrodt, Xalostoc, Mexico) at concentrations of 3.25\% (w/v) and $0.2250 \mathrm{~mol} \mathrm{~L}^{-1}$, respectively, and the solvent was methanol. A stock standard solution of $5.000 \mathrm{mg} \mathrm{L}^{-1}$ of urea (Sigma, >99\%) was prepared daily using methanol as solvent. Working solutions of urea were prepared daily by appropriate dilution of the stock solution with methanol.

\section{Samples}

Seven skin moisturizer creams containing concentrations of urea from 1 to $10 \%$ (w/w) were purchased from local stores and were used to evaluate the performance of the method. Samples A, B, C, D, and E were obtained from pharmacies, while samples F and G were purchased in drugstores.

\section{Sample preparation}

A total of 70 to $260 \mathrm{mg}$ of the moisturizer creams was used to obtain solutions with concentrations in the linear range from 25 to $750 \mathrm{mg} \mathrm{L}^{-1}$. The samples were dissolved in $25 \mathrm{~mL}$ of methanol using sonication. The solutions were then characterized by the spot test and reflectance measurements using the chromogenic reagent.

\section{Experimental design}

After identification of the significant parameters, the operational variables were optimized by multivariate analysis using a full factorial design $\left(2^{3}\right)$ to obtain the optimum analytical conditions. The variables included were the concentrations of $p$-dimethylaminocinnamaldehyde, hydrochloric acid, and sodium dodecyl sulfate. Matrix design and central composite design were performed using Minitab 16, and optimization graphs were constructed using Statistica 8.0. Central composite design was performed using the most influential variables ( $p$-dimethylaminocinnamaldehyde and $\mathrm{HCl}$ ).

\section{Spot test}

The solutions were spotted on $2.25 \mathrm{~cm}^{2}$ filter paper (Whatman No. 1). A $20 \mu \mathrm{L}$ aliquot of the chromogenic reagent solution was spotted first, followed immediately by the addition of $20 \mu \mathrm{L}$ of urea at concentrations from 25 to $750 \mathrm{mg} \mathrm{L}^{-1}$. The solutions were spotted on the center of the filter paper using a micropipette fixed in a holder, according to the 
procedure described by Tubino, Rossi, and Magalhães (1997). The reflectance measurements were performed at $530 \mathrm{~nm}$. A blank was prepared using $20 \mu \mathrm{L}$ of the chromogenic reagent solution and $20 \mu \mathrm{L}$ of methanol. Under these conditions, a uniform color spot was obtained on the surface; this was necessary to ensure accurate and repeatable reflectance measurements, as noted by Wendlandt and Hecht (1966).

\section{Analytical curves}

Calibration curves were constructed using standard solutions of urea in methanol at 25,50 , $100,200,300,500$, and $750 \mathrm{mg} \mathrm{L}^{-1}$ while maintaining the $p$-dimethylaminocinnamaldehyde concentration at $3.258 \%(\mathrm{w} / \mathrm{v})$. The solutions were acidified with $0.501 \mathrm{~mol} \mathrm{~L}^{-1}$ hydrochloric acid and the reaction was performed for $5 \mathrm{~min}$ at $25 \pm 4^{\circ} \mathrm{C}$. All points were measured in triplicate.

\section{Official method}

The urea concentration was determined according to the method established by the Association of Official Analytical Chemists (AOAC) to quantify total nitrogen. The Kjeldahl digestion converted nitrogen compounds to ammonium salts. Free ammonia was released by the addition of sodium hydroxide and determined by backtitration.

\section{Results and discussion}

The reaction between urea and p-dimethylaminocinnamaldehyde in acid proceeds by condensation of the protonated amino group with the carbonyl group of the chromogenic reagent, generating an iminium salt with resonant quinoid structure (Long and Winefordner 1983; Ogura et al. 1999). The influence of solvent was evaluated using methanol and ethanol. The absorbance of the colored reaction product was 10 times higher in methanol compared to ethanol. The influence of a micellar medium was characterized using sodium dodecyl sulfate as the surfactant to increase the sensitivity of colorimetric reactions (Doronin, Chernova, and Gusakova 2005).

\section{Full factorial design}

A full factorial design was used to establish the conditions to maximize the absorbance at $530 \mathrm{~nm}$. First, a $2^{3}$ factorial design was performed, which enabled identification of the factors that affected the reaction (Myers, Montgomery, and Anderson-Cook 2009). Table 2

Table 2. Full factorial design matrix.

\begin{tabular}{lccc}
\hline Experiment & $p$-Dimethylaminocinnamaldehyde $(\%, \mathrm{w} / \mathrm{v})$ & $\mathrm{HCl}\left(\mathrm{mol} \mathrm{L}^{-1}\right)$ & Sodium dodecyl sulfate $\left(\mathrm{mmol} \mathrm{L}^{-1}\right)$ \\
\hline 1 & $0.20(-1)$ & $0.06(-1)$ & $5.00(-1)$ \\
2 & $1.00(+1)$ & $0.06(-1)$ & $5.00(-1)$ \\
3 & $0.20(-1)$ & $0.50(+1)$ & $5.00(-1)$ \\
4 & $1.00(+1)$ & $0.50(+1)$ & $5.00(-1)$ \\
8 & $0.20(-1)$ & $0.06(-1)$ & $12.00(+1)$ \\
6 & $1.00(+1)$ & $0.06(-1)$ & $12.00(+1)$ \\
7 & $0.20(-1)$ & $0.50(+1)$ & $12.00(+1)$ \\
8 & $1.00(+1)$ & $0.50(+1)$ & $12.00(+1)$ \\
\hline
\end{tabular}


shows the factorial design matrix with the different levels of the factors: $p$-dimethylaminocinnamaldehyde $(0.20$ and $1.00 \% \mathrm{w} / \mathrm{v}), \mathrm{HCl}\left(0.06\right.$ and $\left.0.50 \mathrm{~mol} \mathrm{~L}^{-1}\right)$ and sodium dodecyl sulfate $\left(5.00\right.$ and $\left.12.00 \mathrm{mmol} \mathrm{L}^{-1}\right)$. The reaction between the analyte and chromogenic reagent should occur in acid, and surfactants may increase the sensitivity of the reaction. For each factor evaluated, an upper $(+1)$ and a lower $(-1)$ levels were selected, based on the results of preliminary experiments. Eight measurements were performed with the urea concentration constant at $200 \mathrm{mg} \mathrm{L}^{-1}$.

The individual effects of parameters as well as their interactions are illustrated in the Pareto chart in Figure 1. The value of each bar corresponds to the value of the associated regression coefficient. The bars that cross the dashed line, which denotes the $95 \%$ confidence interval boundary, indicate a significant effect. The effects of all parameters and interactions were standardized as each effect was divided by its standard error. The order in which the bars are displayed corresponds to the order of the size of the effect. Figure 1 shows that the chromogenic reagent and the acid concentrations were the most significant factors. The chromogenic reagent showed a positive effect, indicating that the best results were obtained when this factor was adjusted to the highest level $(+1)$. The individual effect of $\mathrm{HCl}$ concentration was also significant but with a negative effect in response to any increase. The score for the individual effect of sodium dodecyl sulfate concentration did not indicate a significant influence on the reaction. Hence, a fixed value was selected, ensuring that the reaction could proceed, while minimizing consumption of the reagent. The interactions between the factors did not significantly influence the response.

\section{Central composite design}

Based on the results obtained using the full factorial design, central composite design (Myers, Montgomery, and Anderson-Cook 2009) was performed to identify the optimum concentrations of the variables that were most influential in the reaction, namely, p-dimethylaminocinnamaldehyde and $\mathrm{HCl}$ (Table 3, Figure 2). The points of a central

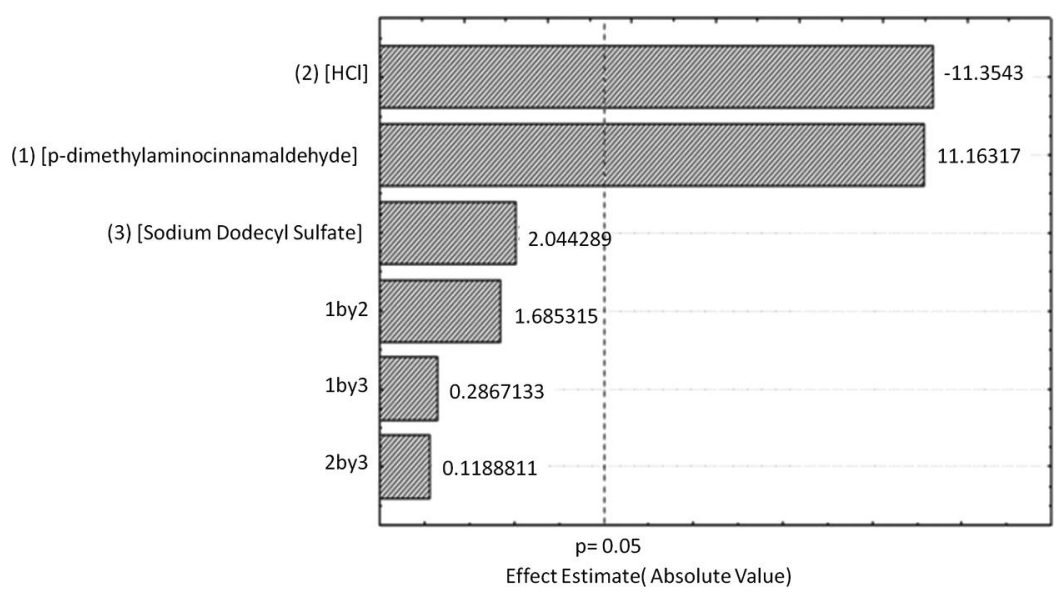

Figure 1. Pareto chart of the optimization using a 23 fractional factorial design. The factors were 0.20 and $1.00 \%(\mathrm{w} / \mathrm{v}) \quad p$-dimethylaminocinnamaldehyde, 0.06 and $0.50 \mathrm{~mol} \mathrm{~L}^{-1} \mathrm{HCl}$, and 5.00 and $12.00 \mathrm{mmol} \mathrm{L}^{-1}$ sodium dodecyl sulfate. The urea concentration was $200 \mathrm{mg} \mathrm{L}^{-1}$. 
Table 3. Matrix obtained from the coordinates of the central composite design points.

\begin{tabular}{|c|c|c|}
\hline \multirow[b]{2}{*}{ Experiment } & \multicolumn{2}{|l|}{ Factor } \\
\hline & $p$-Dimethylaminocinnamaldehyde $(\%, \mathrm{~m} / \mathrm{v})^{a}$ & $\mathrm{HCl}\left(\mathrm{mol} \mathrm{L}^{-1}\right)^{a}$ \\
\hline 1 & $0.866(-1)$ & $0.053(-1)$ \\
\hline 2 & $2.634(+1)$ & $0.053(-1)$ \\
\hline 3 & $0.866(-1)$ & $0.258(+1)$ \\
\hline 4 & $2.634(+1)$ & $0.258(+1)$ \\
\hline 5 & $0.500(-\sqrt{2})$ & $0.155(0)$ \\
\hline 6 & $3.000(+\sqrt{2})$ & $0.155(0)$ \\
\hline 7 & $1.750(0)$ & $0.010(-\sqrt{2})$ \\
\hline 8 & $1.750(0)$ & $0.300(+\sqrt{2})$ \\
\hline 9 & $1.750(0)$ & $0.155(0)$ \\
\hline 10 & $1.750(0)$ & $0.155(0)$ \\
\hline 11 & $1.750(0)$ & $0.155(0)$ \\
\hline 12 & $1.750(0)$ & $0.155(0)$ \\
\hline 13 & $1.750(0)$ & $0.155(0)$ \\
\hline
\end{tabular}

${ }^{a}$ Coded values are shown in parentheses.

composite design were coded values $\sqrt{2}$ distant from the central point (coded as zero); consequently, all points were located on the circumference of a circle with radius $\sqrt{2}$. Table 3 shows the central composite design matrix. The tridimensional response surface graph obtained from fitting of the experimental data is shown in Figure 2. The quadratic regression model is given by:

$$
Z=0.3942+0.0541 x-0.0225 x^{2}+3.4534 y-10.6456 y^{2}+0.4110 x y
$$

where $Z$ is the response factor corresponding to the absorbance, and the factors $x$ and $y$ are the chromogenic reagent and $\mathrm{HCl}$ concentrations, respectively.

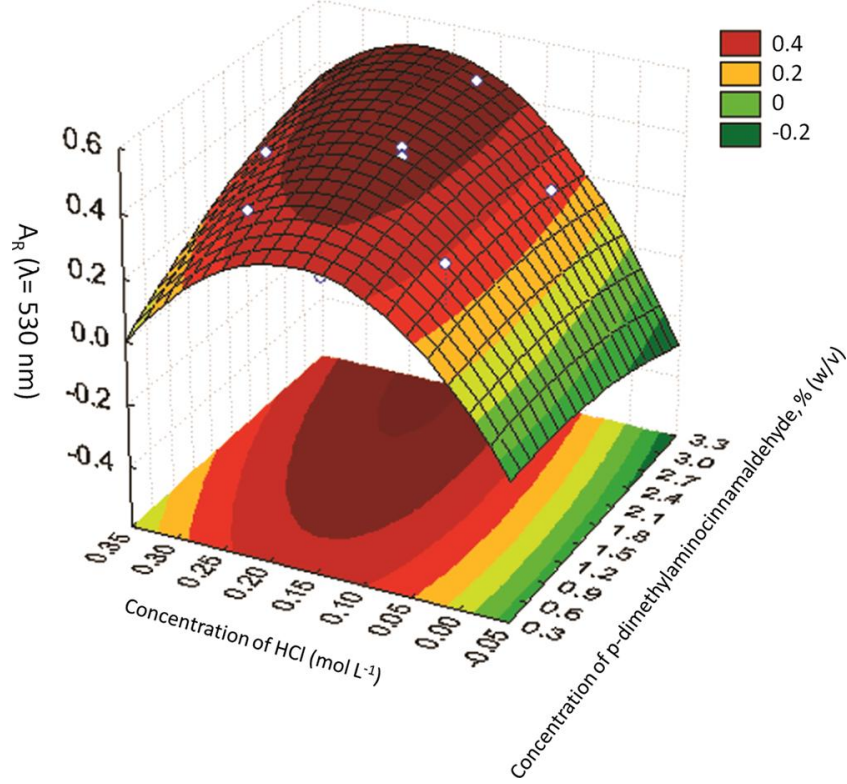

Figure 2. Response surface obtained for absorbance at $530 \mathrm{~nm}$ as functions of the $p$-dimethylaminocinnamaldehyde and $\mathrm{HCl}$ concentrations. 
The critical values of the $p$-dimethylaminocinnamaldehyde and $\mathrm{HCl}$ concentrations, obtained from the response surface graph in Figure 2, were $3.258 \%(\mathrm{~m} / \mathrm{v})$ and $0.2250 \mathrm{~mol} \mathrm{~L}^{-1}$, respectively. The results, and solubility and costs of the reagents show that the chromogenic reagent concentrations increased asymptotically in the central composite design, reaching values for which the absorbance increase was insignificant. The absorbance at the estimated critical point was close to the actual maximum absorbance. Hence, an increase in the chromogenic reagent concentration above the critical point did not significantly increase the absorbance.

\section{Optical stability}

The optical stability of the colored product on the filter paper was determined by measuring the reflectance at $530 \mathrm{~nm}\left(A_{R}\right)$ every $5 \mathrm{~min}$ for $1 \mathrm{~h}$. The results demonstrate that the colored product was stable during the period evaluated.

\section{Analytical figures of merit}

A linear relationship was obtained by plotting the reflectance at $530 \mathrm{~nm}$ as a function of the logarithm of the urea concentration $\left(\log \left[\mathrm{urea}\left(\mathrm{mol} \mathrm{L}^{-1}\right) \times 10^{4}\right]\right)$ with a correlation coefficient of 0.99365 (Figure 3). A factor of $10^{4}$ was used to linearize the analytical curve, with logarithmic values higher than zero. The absorption values were recorded against the reagent blank by measuring the reflectance at $530 \mathrm{~nm}$ (Figure 4). The limits of detection (LOD) and quantification (LOQ) were calculated according to the IUPAC recommendations: $\mathrm{LOD}=3 \mathrm{~S}_{\mathrm{b}} / \mathrm{b}$ and $\mathrm{LOQ}=10 \mathrm{~S}_{\mathrm{b}} / \mathrm{b}$, where $\mathrm{S}_{\mathrm{b}}$ is the standard deviation of blank measurements $(n=10)$ and $b$ is the slope of the calibration. The sensitivity was consistent and below the urea concentration present in the skin moisturizers. The precision, expressed as the relative standard deviation of an analytical response, should be lower than $3.5 \%$.

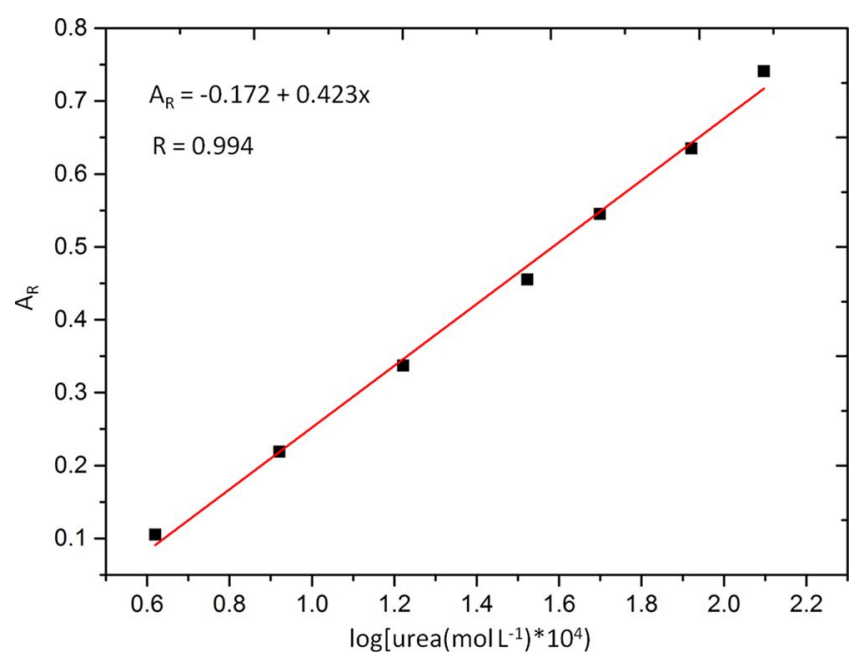

Figure 3. Analytical curve for urea. 


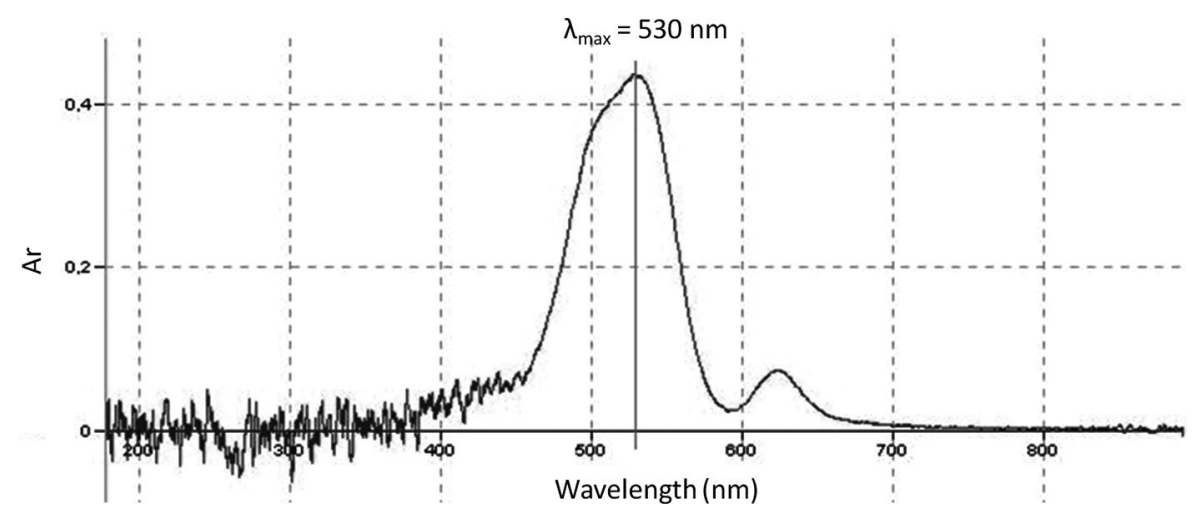

Figure 4. Absorption spectra for the product of reaction of $200 \mathrm{mg} \mathrm{L}^{-1}$ urea with $p$-dimethylaminocinnamaldehyde solution.

Here, the precision was assessed by replicate measurements of the standards at several times in one day (intra-day) and on different days (inter-day). Table 4 lists the analytical figures of merit obtained for the technique. The results indicate that the system was sufficiently sensitive for the determination of urea in skin moisturizer.

\section{Recovery}

The recovery was used to evaluate the accuracy and to identify possible matrix interferences. Two moisturizers were fortified with $25.0,37.5,50.0,62.5$, and $75.0 \mathrm{mg} \mathrm{L}^{-1}$ of urea and each was analyzed thrice. The results are shown in Table 5 . The recoveries were between 91.0 and $108.0 \%$, indicating good accuracy and the absence of matrix effects.

\section{Determination of urea in moisturizer creams}

The efficiency of the reported methodology was evaluated by analyzing seven moisturizer creams containing urea at concentrations from 1 to $10 \%$. The creams also contained cetearyl alcohol, cetearyl 20, mineral oil, lanolin alcohol, petrolatum, acetylated lanolin alcohol, methylparaben, propylparaben, propylene glycol, and deionized water. None of these other components significantly affected the reaction of the analyte with the chromogenic reagents. The results obtained for the analysis of urea in the moisturizer creams using the combined spot test and diffuse reflectance method are provided in Table 6.

The urea concentrations shown on the labels of the moisturizer creams were consistent with the values determined experimentally using the new methodology. The results obtained using the new method were compared statistically using $t$-tests and $\mathrm{F}$ tests, at a 95\% confidence level with those obtained using the comparative method, and showed good agreement. The calculated $t$ values did not exceed the critical values, indicating that there was no significant difference in terms of precision and accuracy. 


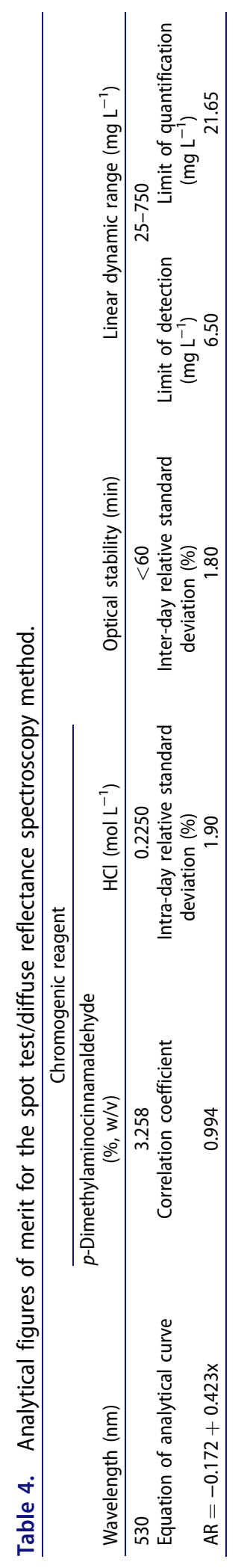


Table 5. Recovery of urea added to moisturizer $(n=3)$.

\begin{tabular}{|c|c|c|c|c|c|}
\hline \multicolumn{3}{|l|}{ Sample A } & \multicolumn{3}{|c|}{ Sample F } \\
\hline $\begin{array}{l}\text { Added value } \\
\left(\mathrm{mg} \mathrm{L}^{-1}\right)\end{array}$ & $\begin{array}{l}\text { Measured value } \\
\quad\left(\mathrm{mg} \mathrm{L}^{-1}\right) \mathrm{a}\end{array}$ & Recovery (\%) & $\begin{array}{l}\text { Added value } \\
\left(\mathrm{mg} \mathrm{L}^{-1}\right)\end{array}$ & $\begin{array}{l}\text { Measured value } \\
\quad\left(\mathrm{mg} \mathrm{L}^{-1}\right) \mathrm{a}\end{array}$ & $\begin{array}{c}\text { Recovery } \\
(\%)\end{array}$ \\
\hline 25.00 & $25.71 \pm 1.2$ & 102.8 & 25.00 & $24.60 \pm 1.3$ & 98.4 \\
\hline 37.00 & $34.08 \pm 1.4$ & 91.0 & 37.00 & $36.30 \pm 1.4$ & 98.1 \\
\hline 50.00 & $46.33 \pm 0.4$ & 93.0 & 50.00 & $47.20 \pm 0.6$ & 94.4 \\
\hline 62.00 & $65.12 \pm 0.7$ & 104.0 & 62.00 & $63.60 \pm 1.2$ & 102.6 \\
\hline 75.00 & $81.17 \pm 0.9$ & 108.0 & 75.00 & $72.80 \pm 0.8$ & 97.1 \\
\hline
\end{tabular}

Table 6. Determination of urea in moisturizer cream.

\begin{tabular}{lcccc}
\hline $\begin{array}{l}\text { Moisturizer and } \\
\text { urea content }(\%, w / w)\end{array}$ & $\begin{array}{c}\text { Official method } \\
(\%, w / w)\end{array}$ & $\begin{array}{c}\text { Reported method } \\
(\% \mathrm{w} / \mathrm{w})\end{array}$ & $\begin{array}{c}t \text {-test } \\
(4.303)^{b}\end{array}$ & $\begin{array}{c}\mathrm{F} \text { test } \\
(19.00)^{b}\end{array}$ \\
\hline A 1\% & $0.88 \pm 0.03^{a}$ & $0.99 \pm 0.08$ & 1.81 & 0.14 \\
B 3\% & $2.70 \pm 0.08$ & $2.97 \pm 0.28$ & 1.27 & 0.07 \\
C 5\% & $4.00 \pm 0.15$ & $4.25 \pm 0.39$ & 1.63 & 0.14 \\
D 5\% & $5.05 \pm 0.05$ & $4.62 \pm 0.33$ & 1.97 & 0.02 \\
E 10\% & $10.90 \pm 0.36$ & $9.93 \pm 0.60$ & 2.60 & 0.35 \\
F 10\% & $10.23 \pm 0.15$ & $10.87 \pm 0.51$ & 2.43 & 0.09 \\
G 10\% & $11.10 \pm 0.10$ & $11.20 \pm 0.17$ & 1.76 & 0.34 \\
\hline
\end{tabular}

${ }^{a_{ \pm}}$Standard deviation, $\mathrm{n}=3 ;{ }^{b}$ Critical values of $\mathrm{t}$ at $95 \%$ confidence level.

\section{Conclusion}

This work demonstrates the feasibility of diffuse reflectance spectroscopy for the quantification of urea in skin moisturizer creams using a spot test on filter paper. The developed method offers advantages compared to literature methods. It is inexpensive, sensitive with a low detection limit of $6.50 \mathrm{mg} \mathrm{L}^{-1}$, precise, accurate, and operationally simple. Furthermore, this approach is portable, provides rapid measurements in $10 \mathrm{~min}$ with low operating cost, and is environmentally friendly because it requires minimal quantities of samples, reagents, and solvents. The official Kjeldahl method for determining urea in cosmetics and dermatological formulations requires about $3 \mathrm{~h}$ for each analysis, offers poor selectivity, requires lengthy pretreatment steps to remove interfering species, and necessitates the use of high temperature and concentrated acids, which can present risks to the operator. The methodology described here contributes to the evolution of eco-friendly technologies.

\section{Acknowledgments}

The authors would like to thank the Brazilian National Research Council (CNPq), the Coordination for the Improvement of Higher Level Personnel (CAPES), and the São Paulo Research Foundation (FAPESP, process $n^{\circ} 2015 / 21733-1$ ) for financial support.

\section{References}

Ademola, J., C. Frazier, S. J. Kim, C. Theaux, and X. Saudez. 2002. Clinical evaluation of $40 \%$ urea and $12 \%$ ammonium lactate in the treatment of xerosis. American Journal of Clinical Dermatology 3:217-22. doi:10.2165/00128071-200203030-00007

Anastas, P. T., and M. M. Kirchhoff. 2002. Origins, current status, and future challenges of green chemistry. Accounts of Chemical Research 35:686-94. doi:10.1021/ar010065m 
AOAC (Association of Official Analytical Chemists). 2000. Official methods of analysis. 17th ed. Washington, DC: AOAC.

Bojic, J., B. Radovanovic, and J. Dimitrijevic. 2008. Spectrophotometric determination of urea in dermatologic formulations and cosmetics. Analytical Sciences 24:769-74. doi:10.2116/analsci. 24.769

Buraczewska, I., B. Berne, M. Lindberg, H. Törmä, and M. Lodén. 2007. Changes in skin barrier function following long-term treatment with moisturizers, a randomized controlled trial. British Journal of Dermatology 156:492-98. doi:10.1111/j.1365-2133.2006.07685.x

Capiau, S., L. S. Wilk, M. C. Aalders, and C. P. Stove. 2016. A novel, non-destructive, dried blood spot-based hematocrit prediction method using non-contact diffuse reflectance spectroscopy. Analytical Chemistry 88:6538-46. doi:10.1021/acs.analchem.6b01321

Clark, S., P. S. Francis, X. A. Conlan, and N. W. Barnett. 2007. Determination of urea using high-performance liquid chromatography with fluorescence detection after automated derivatisation with xanthydrol. Journal of Chromatography A 1161:207-13. doi:10.1016/j.chroma.2007.05.085

Couto, S. G., M. S. Oliveira, and A. Alonso. 2005. Dynamics of proteins and lipids in the stratum corneum: Effects of percutaneous permeation enhancers. Biophysical Chemistry 116:23-31. doi:10.1016/j.bpc.2005.01.009

Dallet, P., L. Labat, E. Kummer, and J. P. Dubost. 2002. Determination of urea, allantoin and lysine pyroglutamate in cosmetic samples by hydrophilic interaction chromatography. Journal of Chromatography B: Biomedical Sciences and Applications 742:447-52. doi:10.1016/s0378-4347 (00)00196-1

Doi, T., K. Kajimura, S. Takatori, N. Fukui, S. Taguchi, and S. Iwagami. 2009. Simultaneous measurement of diazolidinyl urea, urea, and allantoin in cosmetic samples by hydrophilic interaction chromatography. Journal of Chromatography B 877 (10):1005-10. doi:10.1016/j.jchromb.2009.02.032

Doronin, S. Y., R. K. Chernova, and N. N. Gusakova. 2005. Analytical aspects of reactions of primary aromatic amines with p-dimethylaminocinnamic aldehyde in the presence of surfactant ions and micelles. Journal of Analytical Chemistry 60:412-19. doi:10.1007/s10809-005-0111-0

Ehiwe, T. O., B. D. Alexander, J. C. Mitchell, M. J. Snowden, and L. J. Waters. 2016. Monitoring real time polymorphic transformation of sulfanilamide by diffuse reflectance visible spectroscopy. Journal of Pharmaceutical Analysis 6:179-83. doi:10.1016/j.jpha.2015.12.002

Elias, P. M. 2007. The skin barrier as an innate immune element. In Seminars in Immunopathology. 29:1-3. doi:10.1007/s00281-007-0060-9

FDA (Food; and Drug Administration). 2006. Frequency of use of cosmetic ingredient. FDA database. Washington, DC: FDA.

Fluhr, J. W., M. Miteva, G. Primavera, M. Ziemer, P. Elsner, and E. Berardesca. 2006. Functional assessment of a skin care system in patients on chemotherapy. Skin Pharmacology and Physiology 20:253-59. doi:10.1159/000104423

Gotardo, M. A., C. Gigante, L. Pezza, and H. R. Pezza. 2004. Determination of furosemide in pharmaceutical formulations by diffuse reflectance spectroscopy. Talanta 64:361-65. doi:10.1016/ j.talanta.2004.02.034

Iida, Y., M. Ikeda, M. Aoto, and I. Satoh. 2004. Fluorometric determination of urea in alcoholic beverages by using an acid urease column-FIA system. Talanta 64:1278-82. doi:10.1016/ j.talanta.2004.06.021

Inagaki, T., D. Nozawa, Y. Shimomur, and S. Tsuchikawa. 2016. Three fiber-based diffuse reflectance spectroscopy for estimation of total solid content in natural rubber latex. Journal of Near Infrared Spectroscopy 24:327-35. doi:10.1255/jnirs.1227

Knorst, M. T., R. Neubert, and W. Wohlrab. 1997. Analytical methods for measuring urea in pharmaceutical formulations. Journal of Pharmaceutical and Biomedical Analysis 15:1627-32. doi:10.1016/s0731-7085(96)01978-4

Koncki, R., A. Chudzik, and I. Walcerz. 1999. Urea determination using pH-enzyme electrode. Journal of Pharmaceutical and Biomedical Analysis 21 (1):51-57. doi:10.1016/s0731-7085(99) 00094-1

Küster, W., K. Bohnsack, F. Rippke, H. J. Upmeyer, S. Groll, and H. Traupe. 1997. Efficacy of urea therapy in children with ichthyosis. Dermatology 196:217-22. doi:10.1159/000017902 
Lima, L. S., P. L. Weinert, S. C. Lemos, R. Sequinel, H. R. Pezza, and L. Pezza. 2009. An environmentally friendly reflectometric method for ranitidine determination in pharmaceuticals and human urine. Spectrochimica Acta 71:1999-2004. doi:10.1016/j.saa.2008.07.036

Lodén, M. 1996. Urea-containing moisturizers influence barrier properties of normal skin. Archives of Dermatological Research 288:103-07. doi:10.1007/s004030050031

Loden, M., A. C. Andersson, C. Andersson, T. Frödin, H. Öman, and M. Lindberg. 2001. Instrumental and dermatologist evaluation of the effect of glycerine and urea on dry skin in atopic dermatitis. Skin Research and Technology 7:209-13. doi:10.1034/j.1600-0846.2001.070401.x

Lodén, M. A. 2003. Role of topical emollients and moisturizers in the treatment of dry skin barrier disorders. American Journal of Clinical Dermatology 4:771-88. doi:10.2165/00128071-20030411000005

Long, G. L., and J. D. Winefordner. 1983. Limit of detection. A closer look at the IUPAC definition. Analytical Chemistry 55:712-24. doi:10.1021/ac00258a724

Luiz, V. H. M., L. Pezza, and H. R. Pezza. 2012. Determination of nitrite in meat products and water using dapsone with combined spot test/diffuse reflectance on filter paper. Food Chemistry 134:2546-51. doi:10.1016/j.foodchem.2012.04.068

Myers, R. H., D. C. Montgomery, and C. M. Anderson-Cook. 2009. Response surface methodology: Process and product optimization using designed experiments. New Jersey, USA: John Wiley \& Sons.

Ogura, K., K. Nakaoka, M. Nakayama, M. Kobayashi, and A. Fujii. 1999. Thermogravimetry/mass spectrometry of urease-immobilized sol-gel silica and the application of such a urease-modified electrode to the potentiometric determination of urea. Analytica Chimica Acta 384:219-25. doi:10.1016/s0003-2670(98)00821-6

Okparanma, R. N., F. Coulon, and A. M. Mouazen. 2014. Analysis of petroleum-contaminated soils by diffuse reflectance spectroscopy and sequential ultrasonic solvent extraction-gas chromatography. Environmental Pollution 184:298-305. doi:10.1016/j.envpol.2013.08.039

Rahoui, N., B. Jiang, H. T. Pan, and Y. D. Huang. 2016. Spectroscopy strategy for solid propellants quality control. Applied Spectroscopy Reviews 51:431-50. doi:10.1080/05704928.2016. 1145124

Rossini, E. L., M. I. Milani, L. Pezza, and H. R. Pezza. 2016. A new eco-friendly methodology for the determination of Amaranth dye in foodstuffs using diffuse reflectance spectroscopy. Analytical Methods 8:4086-92. doi:10.1039/c5ay02723c

Sáez-Plaza, P., T. Michałowski, M. J. Navas, and A. G. Asuero. 2013a. An overview of the Kjeldahl method of nitrogen determination. Part II. Sample preparation, working scale, instrumental finish, and quality control. CRC Critical Reviews in Analytical Chemistry 43:224-72. doi:10.1080/ 10408347.2012.751787

Sáez-Plaza, P., T. Michałowski, M. J. Navas, A. G. Asuero, and S. Wybraniec. 2013b. An overview of the Kjeldahl method of nitrogen determination. Part I. Early history, chemistry of the procedure, and titrimetric finish. CRC Critical Reviews in Analytical Chemistry 43:178-223. doi:10.1080/ 10408347.2012.751786

Serup, J. 1991. A double-blind comparison of two creams containing urea as the active ingredient. Assessment of efficacy and side-effects by non-invasive techniques and a clinical scoring scheme. Acta Dermato-Venereologica 177:34-43.

Tubino, M., A. V. Rossi, and M. E. Magalhães. 1997. Quantitative spot tests of Fe (III), Cr (VI) and $\mathrm{Ni}$ (II) by reflectance measurements. Analytical Letters 30:271-82. doi:10.1080/0003271970 8002802

Wałcerz, I., S. Głąb, and R. Koncki. 1998. Potentiometric enzyme electrode in a flow injection system for the determination of urea in human serum samples. Analytica Chimica Acta 369:129-37. doi:10.1016/s0003-2670(98)00222-0

Wendlandt, W. W., and H. G. Hecht. 1966. Reflectance spectrometry. New York, USA: Interscience.

Wohlrab, W. 1979. Effect of urea on the mechanism of percutaneous permeation. Dermatologica 159:441-50.

Wohlrab, W. 1986. Urea and the skin. Schweizerische Rundschau fur Medizin Praxis 75:201-04. 